\title{
Compreensão após leitura dialógica: efeitos de dicas, sondas e reforçamento diferencial baseados em funções narrativas ${ }^{*}$
}

\section{Comprehension after dialogic reading: effects of prompts, probes and differential reinforcement based on narrative functions}

\section{Comprensión después de la lectura dialógica: efectos de ayuda, sondeos y reforzamiento diferencial basados en funciones narrativas}

\author{
Bianca da Nóbrega Rogoski ${ }^{1}$, Eileen Pfeiffer Flores², Gilberto Gauche ${ }^{3}$, Raquel Freire Coêlho ${ }^{4}$, \\ Carlos Barbosa Alves de Souza ${ }^{5}$
}

[1-4] Universidade de Brasília [5] Universidade Federal do Pará I Título abreviado: Leitura dialógica e compreensão narrativa | Endereço para correspondência: Eileen Pfeiffer Flores - Universidade de Brasília, Secretaria de Coordenação do Programa de Pós-Graduação em Ciências do Comportamento, Instituto de Psicologia, Departamento de Processos Psicológicos Básicos, Caixa Postal 04500, Universidade de Brasília, Campus Darcy Ribeiro, CEP 70910-900, Brasília-DF Email: eileen@unb.br I DOI: 10.18761/pac.2015.6.1.a04

\begin{abstract}
Resumo: A leitura compartilhada é considerada uma importante estratégia de desenvolvimento da linguagem. A leitura dialógica é um tipo de leitura compartilhada em que um adulto lê em voz alta, intercalando a história com diálogos e feedbacks sobre o texto e/ou as ilustrações. Este estudo investigou os efeitos da leitura dialógica sobre a compreensão de um romance infanto-juvenil em dois meninos de 9 e 10 anos. Dados de um estudo anterior com os mesmos participantes demonstraram pouco efeito das intervenções e serviram como linha de base para adaptações no presente estudo, que consistiu em formular perguntas a partir de funções importantes da narrativa e fornecer consequências de acordo com o desempenho da criança. Ambos apresentaram ganhos na compreensão da narrativa quando comparados à linha de base. Os resultados são discutidos em termos da importância, para a compreensão, do planejamento de dicas, sondas e consequências baseadas em dimensões temáticas relevantes da narrativa, aspecto raramente enfatizado em estudos sobre os efeitos da leitura dialógica.
\end{abstract}

Palavras-chave: leitura dialógica, comportamento verbal, compreensão, narrativa 
Abstract: Shared reading is considered an important strategy for language development. Dialogic reading is a type of shared reading in which the adult reads out loud while asking questions and offering feedback about illustrations and text. This study assessed the effects of dialogic reading on comprehension of a children's novel by two boys, aged 9 and 10 . Data collected in a previous study with the same subjects showed little effects of interventions and served as baseline for changes implemented in the present investigation which consisted in improving scaffolding by providing prompts based on important narrative functions and following answers with feedback in accordance with the child's performance. Both showed gains in story comprehension in comparison to baseline data. Results are discussed in light of the importance, for boosting comprehension, of planning prompts, probes and consequences based on relevant thematic dimensions of the story, an aspect seldom underlined in studies on the effects of dialogic reading.

Keywords: dialogic reading, verbal behavior, comprehension, narrative

Resumen: La lectura compartida es considerada una importante estrategia para el desarrollo del lenguaje. Lectura dialógica es un tipo de lectura compartida en la que el adulto lee en voz alta al mismo tiempo en que plantea preguntas y ofrece retroalimentación para las respuestas. Este estudio investigó los efectos de la lectura dialógica en la comprensión de una novela infantil con dos niños de 9 a 10 años de edad. Los datos de un experimento anterior con los mismos participantes mostraron poco efecto de las intervenciones y fueron la base para los ajustes del presente estudio, en que se formularon preguntas a partir de funciones importantes de la narrativa y se proporcionó retroalimentación ajustada al desempeño del niño a cada momento. Ambos mostraron mejoras en la comprensión de la narrativa en comparación con una línea-base. Se discute la importancia, para impulsar la comprensión, de programar ayuda, sondeos y consecuencias a partir de dimensiones temáticas relevantes del texto, aspectos raramente enfatizados en estudios sobre lectura dialógica.

Palabras-clave: lectura dialógica, comportamiento verbal, comprensión, narrativa

* Agradecimentos: Os autores agradecem a Bárbara de Souza Araújo, Jéssica Araújo da Conceição e Lucas Moura Barros pela colaboração na coleta de dados; a Vanessa Aparecida Leal Faria e Fabio Hernandez de Medeiros pela colaboração na redação final do manuscrito; e aos dois revisores anônimos por suas importantes considerações.

Agências de fomento: A pesquisa recebeu auxílio do $\mathrm{CNPq}$ (apoio financeiro ao projeto; bolsa de IC para BNR, de Produtividade em Pesquisa para CBAS e de Jovens Talentos para a Ciência para GG). 
Os jovens brasileiros têm demonstrado desempenhos abaixo da média em habilidades leitoras, estando em $55^{\circ}$ lugar de 64 países, segundo dados do PISA (Programme for International Student Assessment), que avalia conhecimentos e habilidades de jovens de 15 anos (OECD, 2013). Uma das estratégias recomendadas por instituições governamentais e não governamentais de vários países para o desenvolvimento dessas habilidades, desde o momento do nascimento da criança, é a leitura compartilhada, em que um adulto lê uma obra de literatura infantil ou infanto-juvenil em voz alta para uma ou mais crianças (e.g. o projeto Espantapajaros, na Colombia e o Programa Nacional de Salas de Lectura, no México, cf. Reyes, 2012; Marques Neto, Venegas, \& Octore, 2013, respectivamente).

Quando é interativa, ou seja, quando são feitas perguntas acerca do texto e das ilustrações e é dado feedback para as verbalizações das crianças, a leitura compartilhada parece ser especialmente benéfica para a formação do leitor (Swanson et al., 2011), incluindo ganhos no vocabulário (e.g., Wasik \& Hindman, 2014), conceitos relacionados a material impresso (print concepts) (e.g., Gettinger \& Stoiber, 2014) e a habilidade de narrar histórias (Lever \& Sénéchal, 2011). No entanto, ainda há poucos dados acerca de seus efeitos sobre a compreensão de narrativas.

Dickinson e Smith (1994) correlacionaram três estilos de leitura interativa (categorizados a partir da observação naturalista de professores em sala) com a aquisição de vocabulário e com a compreensão de narrativas. Seus resultados indicaram que a leitura performática, seguida de discussão aberta, teve correlação com aquisição de vocabulário e com ganhos modestos na compreensão, em comparação com (a) a leitura interrompida por perguntas e diálogo e (b) a leitura didática, composta por tarefas guiadas pelo professor. No entanto, as perguntas feitas durante a condição de leitura intercalada, muitas vezes, não tinham relação relevante com a estrutura da história (por exemplo, perguntas sobre aspectos das ilustrações que eram irrelevantes para a compreensão), enquanto as perguntas feitas ao final da leitura performática tinham relação clara com aspectos importantes da estrutura narrativa. Assim, não é possível separar qual(is) dos aspectos de cada estilo foi responsável pelos resultados. No presente estudo, houve o cuidado com a formulação de perguntas para que fossem relacionadas a aspectos relevantes para a compreensão da narrativa (funções narrativas), bem como com a manutenção do diálogo ao redor da narrativa.

Um tipo de leitura interativa cujos efeitos foram bastante investigados a partir do final dos anos 80 é a assim chamada Leitura Dialógica (LD) (e.g. Whitehurst et al., 1988; Whitehurst et al., 1999; Whitehurst \& Lonigan, 1998; Zevenbergen, Whitehurst, \& Zevenbergen, 2003; para uma revisão, ver Camelo \& Souza, 2009). A LD é caracterizada como a leitura compartilhada de uma obra (geralmente um livro infantil ilustrado), por um adulto para uma ou mais crianças, em que o adulto encoraja a verbalização da(s) criança(s) acerca da história e das ilustrações. São feitas perguntas do tipo "quem, o quê, quando, onde, como e qual", questões sobre as ilustrações do livro, pedidos para antecipar a parte seguinte da história etc. Flynn (2011), ao apresentar orientações para a implementação da LD, recomenda começar com perguntas específicas e, aos poucos, progredir para perguntas mais abertas, de modo que a criança seja cada vez mais ativa na conversa acerca da obra. Além disso, o adulto deve oferecer feedback para as verbalizações das crianças, que incluem elogiar, parafrasear as respostas, ampliá-las com novas informações, dentre outros.

A LD foi conceituada, na literatura, a partir da noção de scaffolding (Van de Pol, Volman, \& Beishuizen, 2010; Pillinger \& Wood, 2013), derivada do conceito de zona de desenvolvimento proximal de Vigotsky (1978/1998). No scaffolding, a ajuda oferecida à criança se adapta ao desempenho dela, momento a momento. Do ponto de vista de uma análise do comportamento verbal, pode-se interpretar o que acontece entre o mediador (adulto que lê o livro em voz alta) e o ouvinte em termos da noção de estimulação suplementar proposta por Skinner (1957), sendo essa apenas uma das características que envolve procedimentos de scaffolding. Dessa forma, os estímulos disponíveis (no caso, o texto sendo lido em voz alta e eventualmente as ilustrações) seriam insuficientes para evocar uma resposta por parte da criança, trazendo a necessidade do fornecimento de prompts (o termo pode 
ser traduzido como dicas no presente contexto), conceituados como aquela estimulação suplementar que é oferecida quando o mediador conhece as respostas que quer evocar. As dicas podem ser formais, ou seja, baseadas em aspectos topográficos da resposta a ser evocada (por exemplo, uma dica ecóica em que se pede para a criança repetir o nome de um personagem) ou temáticas (baseadas em aspectos do que se chamaria do conteúdo ou sentido do texto, e.g., dar a dica de uma parte da história para ajudar a criança a se lembrar de outra). Também pode ser oferecida estimulação suplementar na forma do que Skinner (1957) chamou de probes (sondas), que seriam estímulos complementares dados quando o mediador não tem certeza da resposta que é provável, como se "sondasse" possíveis respostas (por exemplo, quando a criança procura por uma palavra para expressar-se e o mediador, não sabendo ao certo qual é a resposta que está sendo fracamente evocada pelos estímulos presentes, apresenta palavras possíveis que caberiam no contexto). As sondas também podem ser formais ou temáticas.

Quanto aos resultados empíricos obtidos com a LD, uma meta-análise feita por Mol, Bus, Jong e Smeets (2008) evidenciou que a LD produz ganhos no vocabulário receptivo (palavras que a criança consegue compreender) e expressivo (palavras que a criança é capaz de emitir), mas principalmente em crianças de 2-3 anos, não havendo, até então, evidências sólidas para crianças mais velhas nem para efeitos sobre a compreensão de histórias. Considerando essa lacuna, Flores, Pires e Souza (2014) compararam experimentalmente os efeitos da LD com a leitura não-dialógica sobre a compreensão de um romance infanto-juvenil com crianças de 8-9 anos usando um delineamento de linha-de-base múltipla por participante. A compreensão da narrativa foi medida de três maneiras, em ordem decrescente de exigência: tarefa de recontação da história para um ouvinte ingênuo, sem prompts (recontação livre), com prompts (recontação dirigida) e reconhecimento de afirmações, baseadas em pontos cruciais da narrativa, como sendo falsas ou verdadeiras. Os resultados demonstraram ganhos na compreensão da narrativa nas três medidas quando o texto foi lido usando-se a LD, em comparação com a leitura não-dialógica, para duas das crianças.
Para melhor compreender as razões da ausência de efeitos para a terceira criança, foi sugerida a necessidade de se desmembrar empiricamente os componentes de intervenções da LD, separando-se os efeitos de diferentes tipos de perguntas, de forma a compreender melhor as relações entre as intervenções dialógicas e os ganhos na compreensão.

Rogoski et al. (2013) compararam os efeitos sobre a compreensão da narrativa da leitura não-dialógica e da LD, medida em termos de percentual de funções importantes da narrativa presentes em uma tarefa de Reconto Livre, em que era solicitado à criança o relato da história que acabara de ouvir, e em outra de Reconto Dirigido, na qual eram feitas perguntas específicas sobre a narrativa. Houve também a investigação dos efeitos da LD para três categorias de verbalizações (nomear os personagens, caracterizá-los e descrever seus sentimentos e estados de ânimo), usando-se um delineamento de linha-de-base múltipla por comportamento (com as seguintes condições: $\mathrm{A}$ - não dialógica, $\mathrm{B}$ - evocação de nomeação de personagens, $\mathrm{C}$ - evocação de caracterizações, $\mathrm{D}$ - evocação de sentimentos e estados de ânimo de personagens). Os participantes foram dois meninos, de 8 e 9 anos, os mesmos do presente estudo. Os resultados mostraram pouca ou nenhuma evidência de efeitos da LD sobre a compreensão da narrativa, em comparação com a leitura não-dialógica. Tampouco foram evidenciados efeitos sobre as três categorias específicas de verbalizações. As filmagens das sessões e a análise das interações entre o mediador e a criança revelaram alguns aspectos que podem ter afetado os resultados, relacionados à estimulação suplementar e ao reforçamento diferencial.

Com relação à estimulação suplementar, Rogoski et al. (2013) verificaram que os mediadores faziam as perguntas planejadas para ocorrerem durante a leitura, porém, quando a criança não respondia, não eram oferecidas sistematicamente novas dicas e sondas que poderiam favorecer $o$ controle do comportamento verbal pela narrativa. Quando o mediador oferecia alguma estimulação suplementar, geralmente, esta não era tematicamente relacionada a dimensões relevantes da narrativa. Com relação ao reforçamento social para as verbalizações da criança (elogios, seguimento da conversa, comentários acerca do que foi dito), no- 
tou-se que este não foi contingente a respostas sob controle de aspectos relevantes da narrativa, havendo inclusive, uma frequência maior de reforçamento social por parte do mediador quando a criança falava de aspectos não relacionados à narrativa que estava sendo lida.

Considerando a escassez de estudos acerca dos efeitos da LD sobre a compreensão de narrativas, e os resultados contrastantes de Flores et al. (2014) e Rogoski et al. (2013), o presente estudo consistiu em uma continuação do estudo de Rogoski et al. (2013) com os mesmos participantes, porém com uma maior ênfase, ao preparar a mediação de leitura dialógica, sobre a importância de modelar verbalizações sob controle de aspectos funcionalmente relevantes para a compreensão: (1) quando a pergunta planejada não produzisse os efeitos desejados, seriam oferecidas dicas ou sondas objetivando evocar verbalizações sob controle de aspectos tematicamente relevantes da narrativa, antes de oferecer um modelo de resposta, seguindo uma hierarquia de assistência crescente e (2) seriam reforçadas diferencialmente as verbalizações sob controle desses aspectos.

\section{Método}

\section{Participantes}

Participaram Lucas, de 9 anos e Davi, de 10 anos (nomes fictícios), matriculados em uma escola pública do Distrito Federal, no terceiro e quarto ano, respectivamente. Ambos foram indicados pela diretora da escola para participação na pesquisa por apresentarem, segundo a equipe psicopedagógica da escola, dificuldades na compreensão leitora (Davi), na linguagem receptiva (Lucas) e na linguagem expressiva (Lucas e Davi). O projeto que deu lugar ao presente estudo foi aprovado por Comitê de Ética em Pesquisa com Seres Humanos da Faculdade de Saúde da Universidade de Brasília. O termo de consentimento livre e esclarecido foi lido e assinado tanto pelos pais, quanto pelas crianças.

\section{Material e Equipamentos}

Foi lida para as crianças a obra infanto-juvenil "Meu pai é um dragão" da autora Jackie French, com ilustrações de Stephen Michael King, da edi- tora Fundamento, de 2008. Trata-se de obra com predominância de textos e poucas ilustrações, no formato "romance para crianças", ou seja, não contém apenas a narração de eventos mas também aspectos relacionados à atmosfera física e psicológica das cenas, descrições de estados emocionais, pensamentos e outros aspectos psicológicos dos personagens, caracterizações da personalidade dos personagens e situações de conflito e de motivações contraditórias. A obra é da mesma autora e do mesmo ilustrador do livro utilizado em Rogoski et al. (2013) e possui linguagem e nível de dificuldade semelhantes, porém com enredo, setting, personagens, dilemas e conflitos muito diferentes. O livro contém 24 capítulos, tendo sido lido um capítulo por sessão, com exceção da última sessão, em que foram lidos os dois últimos capítulos, totalizando 23 sessões. Todas as sessões foram filmadas com uma câmera digital apoiada sobre um tripé.

Análise do texto e preparação de intervenções para LD e para avaliação de compreensão. Para guiar as perguntas que seriam feitas, as possíveis dicas e sondas que seriam oferecidas quando necessárias e a avaliação do desempenho das crianças, foi realizada uma análise do texto buscando suas dimensões temáticas mais importantes. Para cada capítulo, foram analisados e listados (1) os eventos da narrativa e (2) as funções da narrativa.

As funções da narrativa, segundo Flores et al. (2014), se baseiam no conceito de "unidade funcional da narrativa" de Barthes (1966/2009), sendo cada unidade definida pelo papel que desempenha na narrativa como um todo, e não por suas características formais nem pelo segmento específico do texto. Elas dizem respeito a pontos essenciais da história, ao motivo pelo qual certa expressão, personagem ou evento foi utilizado pelo autor, bem como ao fato de, provavelmente, esse ponto servir de base para a compreensão de alguma passagem futura no decorrer da história. Cor essa noção, procurou-se captar as ideias da narrativa que fossem relevantes para a compreensão, sem as quais o leitor perderia informações importantes e, possivelmente, se perderia no fluxo do texto. A Tabela 1 mostra um trecho de análise dos eventos do Capítulo 1. A Tabela 2 mostra um exemplo de uma função narrativa, uma pergunta para a LD e uma pergunta de compreensão, também referentes ao Capítulo 1. 


\section{Tabela 1 - Exemplo de Análise dos Eventos da Narrativa}

Cenário: Sala de aula do Horácio

Sir Sneazle anuncia dever de casa (ameaça com inspeção do rei, etc.).

Sir Sneazle passa dever de cem páginas.

Bernard questiona fracamente a tarefa.

Professor mantém.

Para Phillip Chiqueiro, Paul Espinhento e Oscar Ferreiro, é dado o dever de salvar uma donzela.

Alunos questionam caráter impossível do dever, professor ignora a todos.

Professor exige do Horácio trazer dragão morto.

Horácio reclama de caráter ilegal do dever.

Professor mantém exigência e ameaça quem não fizer com expulsão.

Professor dispensa a turma.

\section{Tabela 2 - Exemplo de análise de uma Função da Narrativa}

\begin{tabular}{|c|c|c|}
\hline Função narrativa & $\begin{array}{l}\text { Pergunta para diálogo durante a } \\
\text { leitura compartilhada }\end{array}$ & $\begin{array}{l}\text { Pergunta para o Reconto } \\
\text { Dirigido }\end{array}$ \\
\hline $\begin{array}{l}\text { Contrastar personalidades do Sir } \\
\text { Sneazle e do Sir Coelho (Sir Coelho, } \\
\text { ao contrário de Sir Sneazle, era um } \\
\text { professor estimado pelos alunos. } \\
\text { Sir Sneazle dá deveres excessivos e } \\
\text { punições cruéis). }\end{array}$ & $\begin{array}{l}\text { Se você fosse Horácio, de } \\
\text { quem você preferiria ser } \\
\text { aluno, do Sir Coelho ou } \\
\text { do Sir Sneazle? Por quê? }\end{array}$ & $\begin{array}{l}\text { Conte para mim: Como era } \\
\text { o Sir Sneazle? } \\
\text { Por que as crianças se } \\
\text { lembraram tanto do Sir } \\
\text { Coelho durante a aula? }\end{array}$ \\
\hline
\end{tabular}

Vale notar que as funções narrativas não se reduzem aos eventos nem são expressas necessariamente por eles. Elas expressam dimensões temáticas importantes da narrativa, aquelas que devem exercer controle sobre o comportamento verbal de um leitor para que se possa dizer que ele de fato compreendeu o texto. Por exemplo, no romance utilizado neste estudo, o contraste entre as personalidades de dois personagens (Professor Sneazle e Professor Coelho) é expresso, não apenas por meio dos eventos que fazem parte do enredo, mas também por trechos de flashback que esclarecem eventos anteriores à história sendo narrada e sobretudo pela descrição dos sentimentos de horror de outros personagens perante o Prof. Sneazle, por um lado, e das saudades profundas do Prof. Coelho, por outra. Assim, o levantamento das funções narrativas foi a metodologia de análise do texto usada para listar as dimensões temáticas relevantes do texto o que, por sua vez, fundamentou o planejamento das perguntas e dicas durante a leitura e das perguntas para a tarefa de avaliação de compreensão.

\section{Procedimento}

Coleta de dados. A coleta de dados se deu no período de 14/05/2013 a 20/10/2013, 5 meses após a coleta do estudo anterior, duas vezes por semana, na biblioteca da escola, que ficava reservada para a pesquisa nos horários de coleta. Antes de cada sessão, a mediadora de leitura fazia a releitura do capítulo do dia e estudava a análise das funções da narrativa. A mediadora foi instruída a, durante a leitura, ficar atenta à resposta da criança, variando a pergunta até que a criança demonstrasse claramente a compreensão da função narrativa que se desejava enfatizar naquele momento. A mediadora também foi instruída a reforçar as verbalizações que estivessem sob controle dessas dimensões temáticas com demonstrações de interesse e entusiasmos, repetindo, parafraseando, comentando e elogiando as falas relevantes. Complementarmente, a mediadora trazia a criança novamente à história quando esta falava de assuntos não relacionados, instruindo-a explicitamente a falar da história e dando a ela a liberdade de conversar so- 
bre o outro assunto com os pesquisadores ao final da sessão. Caso a criança apresentasse dificuldades para responder a uma pergunta planejada, foram planejados os seguintes passos de assistência crescente: (1) reformular a pergunta com outras palavras; (2) dar novas dicas ou sondas (por exemplo, pedir para a criança relembrar uma parte da história relevante para a resposta desejada); (3) dar modelo de resposta à criança. Caso fosse necessário dar o modelo de resposta, retornava-se à pergunta aberta inicial, encorajando a criança a retomar, com as próprias palavras, a dimensão temática em foco.

Cada sessão durava aproximadamente 30 minutos. O capítulo era lido em voz alta pela mediadora para a criança, dando liberdade para a criança olhar os detalhes do texto e das ilustrações, virar páginas, etc. quando demonstrasse interesse. A leitura era intercalada com as intervenções planejadas e, após a leitura, ocorriam duas atividades para avaliação da compreensão: Reconto Livre e Reconto Dirigido. A mediadora de leitura saía da biblioteca e entrava um segundo pesquisador (sempre o mesmo) que pedia para a criança "contar o que tinha acontecido na história naquele dia" (Reconto Livre). No Reconto Livre, o pesquisador encorajava a criança a continuar contando quando ela parava, demonstrando interesse por meio do contato visual, postura corporal etc., porém não fazia perguntas. Quando a criança terminava, o mesmo pesquisador conduzia o Reconto Dirigido, em que eram feitas perguntas preparadas previamente com base nas funções narrativas. Todas as perguntas do Reconto Dirigido eram abertas, no sentido de não poderem ser respondidas apenas com sim/não. Todas as perguntas eram diferentes daquelas que haviam sido realizadas durante a leitura compartilhada.

Avaliação da Compreensão. Depois de cada sessão, a filmagem do Reconto Livre e do Reconto Dirigido era analisada usando-se uma folha de registro que continha uma tabela com os eventos e outra com as funções narrativas do capítulo, em que os avaliadores marcavam eventos e funções que foram atingidos pela criança. Registrava-se que a criança havia atingido a função ou o evento quando sua narrativa no Reconto Livre ou sua resposta no Reconto Dirigido claramente expressavam a dimensão temática envolvida, independentemente das palavras usadas. Por exemplo, a função de demonstrar o caráter maldoso do Sir Sneazle poderia ser atingida descrevendo-se algumas evidências disso presentes no texto, como o medo que os alunos sentiam dele ou a crueldade dos deveres de casa passados e/ou simplesmente descrevendo-o como muito malvado. Desse modo, a análise da compreensão se deu pelas seguintes medidas: (a) porcentagem de funções (soma das funções narrativas expressas pela criança no Reconto Livre + Perguntas Complementares sobre o total de funções do capítulo, multiplicado por 100); (b) porcentagem de eventos (número de eventos citados pela criança no Reconto Livre + Perguntas Complementares sobre o total de eventos da sessão, multiplicado por 100).

Concordância entre observadores. O teste de concordância entre três avaliadores na avaliação de eventos e funções atingidas foi realizado com uma amostra aleatória de 3 vídeos $(13,04 \%)$ e demonstrou índice de concordância ([concordâncias / concordâncias + discordância] x 100) de 85,13\% para as funções atingidas e 78,5\% para os eventos atingidos. Os avaliadores eram familiarizados com os conceitos de eventos e funções.

\section{Resultados}

Como foi dito, os dados obtidos em Rogoski et al. (2013) foram obtidos com os mesmos participantes e serviram como linha-de-base para o presente estudo (Sessões 1-12, que são apresentadas sem discriminar as condições então vigentes, justamente porque estas não produziram efeitos sobre o desempenho). As Sessões 13 a 35 referem-se ao presente estudo, no qual foi modificado o procedimento de leitura dialógica, conforme explicado na seção de Método.

A Figura 1 mostra a porcentagem de funções narrativas (painel superior) e de eventos (painel inferior) atingidos por Lucas ao longo das sessões, nas tarefas de Reconto Livre e Reconto Dirigido combinadas. A porcentagem de funções atingidas por Lucas foi superior nas Sessões 13 em diante, em comparação às sessões anteriores. A porcentagem máxima de funções atingidas variou entre 0 e $57 \%$ no estudo de Rogoski et al. (2013) e entre 50\% e $100 \%$ no estudo atual, com predominância de va- 


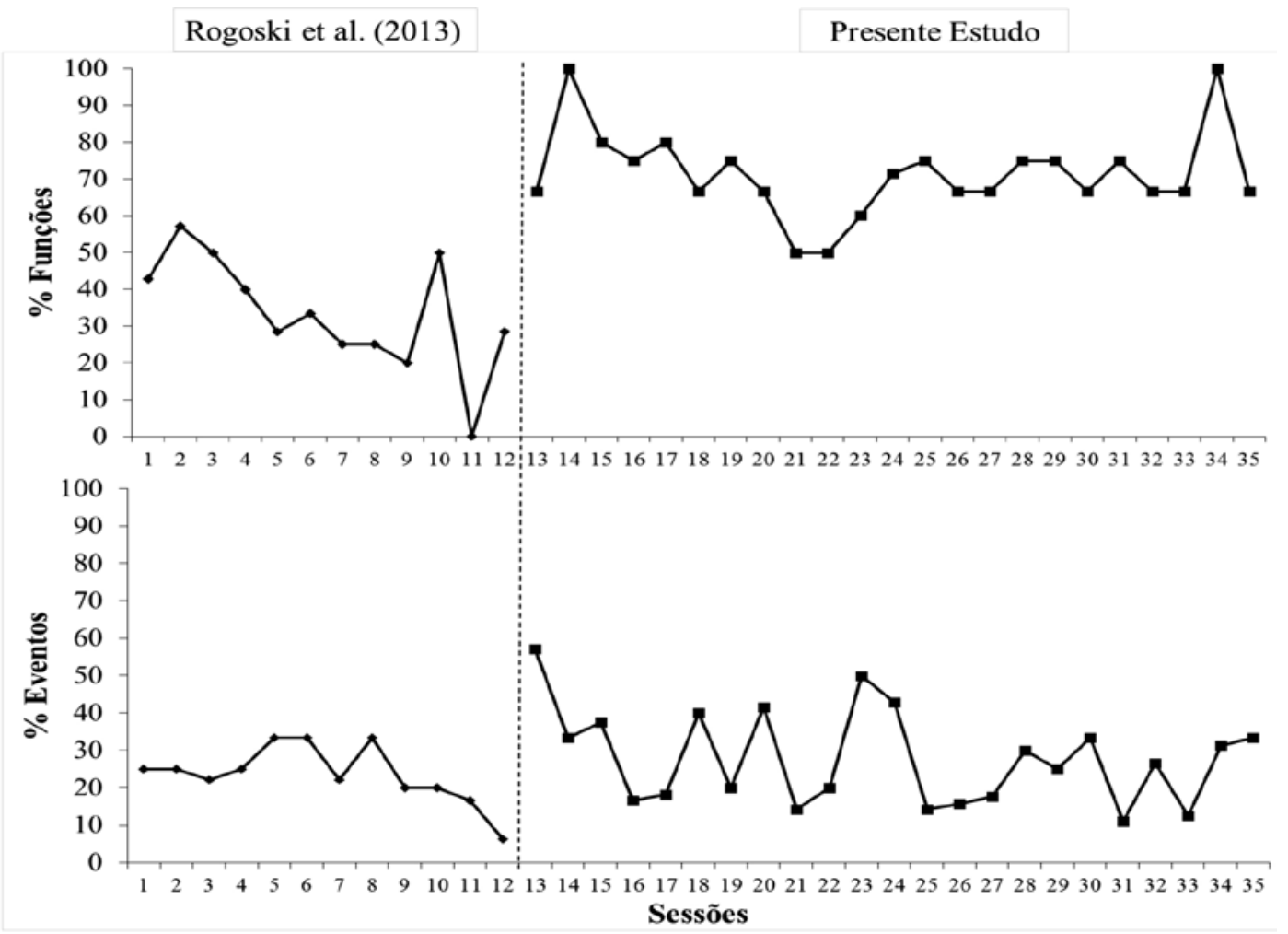

Figura 1. Porcentagem de funções (painel superior) e eventos (painel inferior) atingidos por Lucas nas tarefas de Reconto Livre e Reconto Dirigido combinadas, em Rogoski et al. (2013) (Sessões 1-12) e no presente estudo (Sessões 13-35).

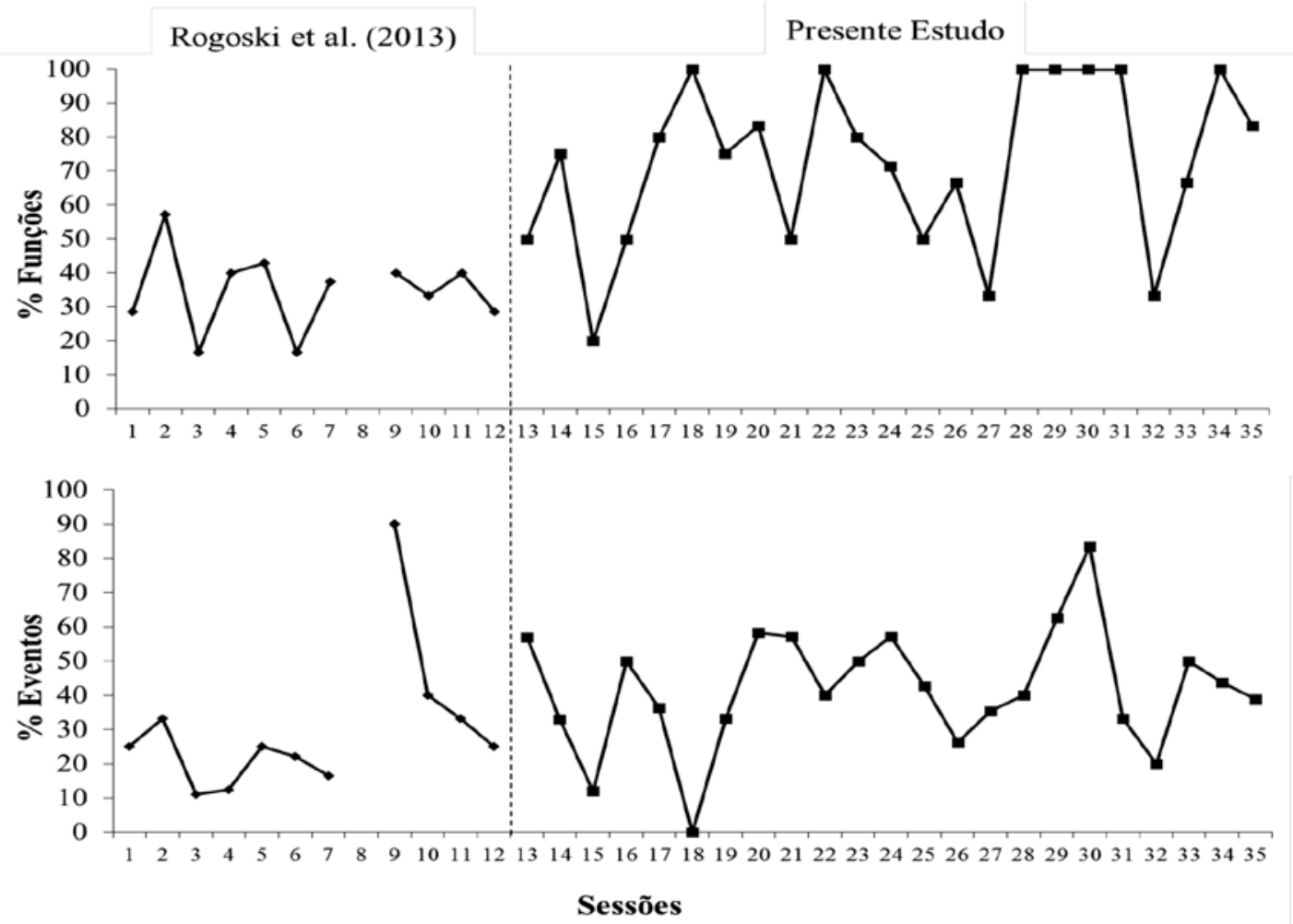

Figura 2. Porcentagem de funções (painel superior) e eventos (painel inferior) atingidos por Davi nas tarefas de Reconto Livre e Reconto Dirigido combinadas, em Rogoski et al. (2013) (Sessões 1-12) e no presente estudo (Sessões 13-35). 
lores ao redor de 70\%. Quanto aos eventos citados, o número de eventos oscilando entre $6 \%$ e $33 \%$ nas sessões de Rogoski et al. (2013) e entre 11\% e 57\% nas sessões do presente estudo.

A Figura 2 mostra a porcentagem de funções (painel superior) e de eventos (painel inferior) atingidos por Davi ao longo das sessões, nas tarefas de Reconto Livre e Reconto Dirigido combinadas. Davi atingiu porcentagem máxima de funções narrativas atingidas de $57 \%$ no estudo de Rogoski et al. (2013), variando entre 17 e $57 \%$. No presente estudo, com exceção das sessões 15, 27 e 32, seu desempenho foi superior ou igual a $50 \%$ das funções atingidas e, em 16 das 24 das sessões, foi superior a $70 \%$, chegando a atingir $100 \%$ em sete delas. Quanto aos eventos, o efeito é menos claro, embora pareça haver uma tendência a ser maior no presen- te estudo, no qual Davi teve um alcance de $40 \%$ ou mais de funções atingidas em $56,52 \%$ das sessões, enquanto no estudo anterior, somente em 18,18\% delas ele atingiu $40 \%$ ou mais das funções nas tarefas de reconto livre e reconto dirigido.

A Tabela 3 apresenta exemplo de interação durante a leitura compartilhada no estudo de Rogoski et al. (2013). A Tabela 4 apresenta exemplo de interação durante uma contação do estudo atual, para efeitos de comparação. Diferentemente de Rogoski et al. (2013), no atual estudo, nota-se que, quando a pergunta planejada não produzia os efeitos desejados, a mediadora fazia outras perguntas, apresentando estimulação suplementar visando evocar verbalizações relacionadas à função narrativa em foco, em detrimento de falas não-relacionadas (e.g. “tia, faz um aviãozinho?”).

\section{Tabela 3 - Exemplo de diálogo em Rogoski et al. (2013) (Função narrativa em foco: alegria e descontração dos piratas).}

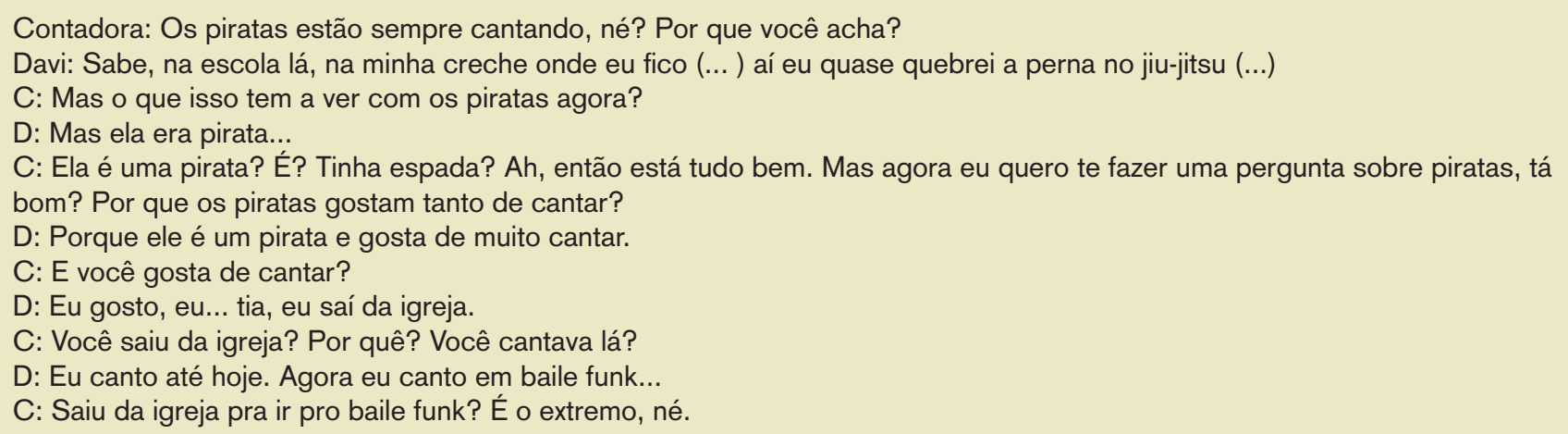

\section{Tabela 4 - Exemplo de diálogo no estudo atual (Função narrativa em foco: sentimentos de Horácio} pelos amigos)

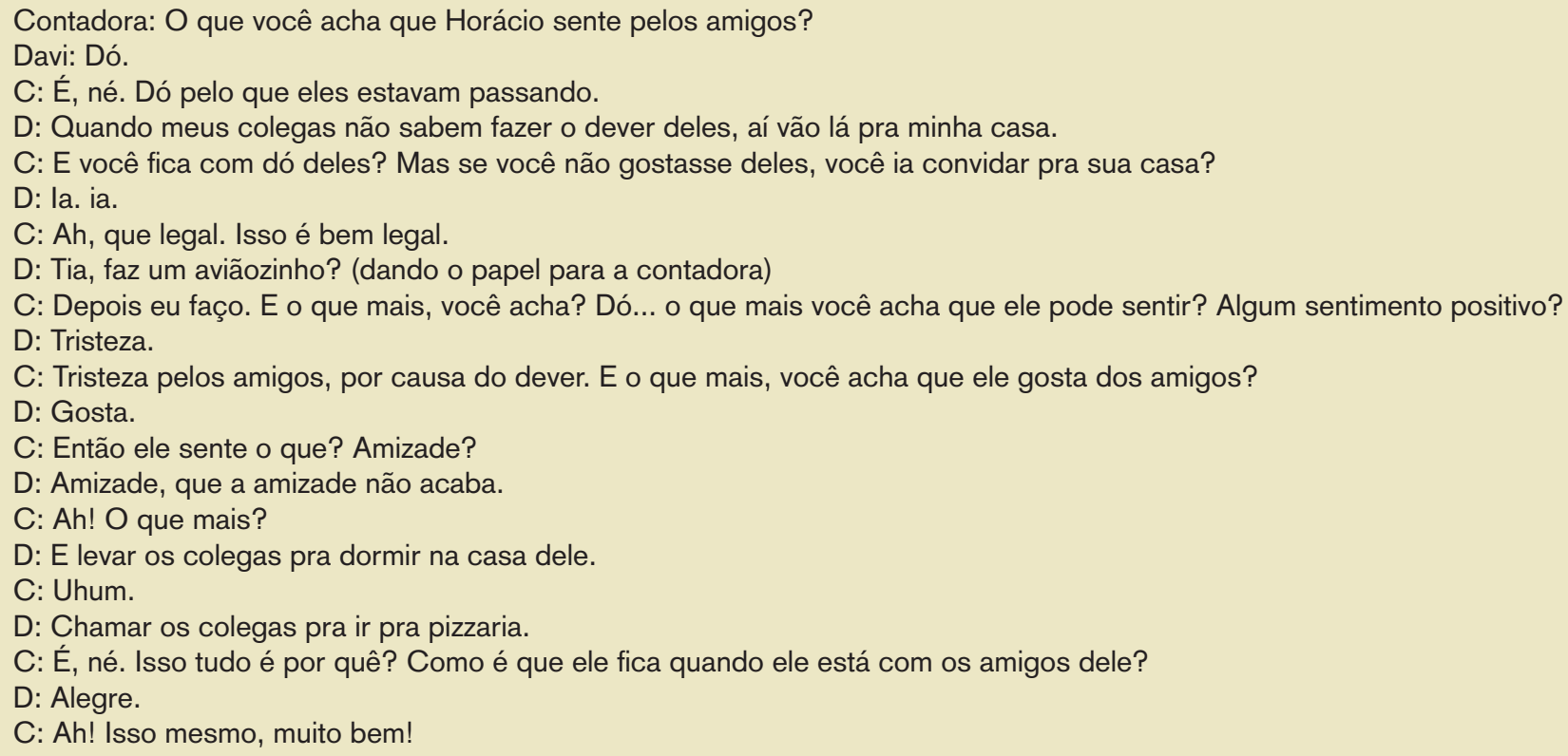




\section{Discussão}

Ambos os participantes mostraram, por meio das tarefas de reconto livre e dirigido, um desempenho melhor no estudo atual, em comparação com Rogoski et al. (2013), em termos das funções narrativas atingidas, após planejamento mais detalhado das intervenções dialógicas (baseadas nas funções narrativas) e treinamento da mediadora, evocando e reforçando verbalizações sob controle temático do texto. Isso sugere que tais mudanças foram importantes para que as falas dos ouvintes ficassem sob controle de relações temáticas do texto.

No entanto, como se trata de um delineamento A-B, é possível levantar a hipótese de que o aumento na porcentagem de funções atingidas se deva apenas ao processo de maturação dos participantes. Outra possibilidade é relacionar os resultados apenas à experiência anterior das crianças com textos e tarefas semelhantes no estudo de Rogoski et al. (2013). Porém, o fato de a porcentagem de eventos atingidos, diferentemente das funções, não ter mostrado aumento tão claro sugere a especificidade do efeito da intervenção, que se focou nas funções narrativas. Se o efeito encontrado pudesse ser atribuído apenas à maturação ou à experiência prévia com textos e tarefas semelhantes, seria provável que se verificasse um desempenho semelhante nas duas medidas. Quanto à experiência prévia com textos e tarefas semelhantes, se esta fosse suficiente para explicar o efeito encontrado, provavelmente se verificaria um aumento gradual no desempenho ao longo de todas as sessões, e não apenas a partir da Sessão 13. Juntos, esses fatores aumentam a confiança de que os resultados possuem relação funcional com as intervenções implementadas e não apenas com variáveis do texto ou fatores maturacionais.

Os resultados sugerem que, para que a leitura dialógica possa ter efeitos positivos sobre a compreensão de narrativas, é necessário apresentar estimulação suplementar e reforçamento diferencial de forma que favoreçam o controle do comportamento verbal do ouvinte por aspectos temáticos relevantes da narrativa. Os dados do estudo de Rogoski et al. (2013), que serviram como linha de base neste estudo, não haviam evidenciado efeitos positivos da leitura dialógica sobre a compreensão da narrativa. Independentemente da condição em vigor (leitura dialógica ou não dialógica), os resultados haviam sido semelhantes ao longo das doze sessões. A análise das interações ocorridas nas condições de leitura dialógica havia sugerido que os diálogos não fundamentavam a compreensão leitora, na medida em que não favoreciam o controle das verbalizações das crianças por aspectos relevantes da narrativa. Isso se assemelha ao que ocorreu no estudo de Dickinson e Smith (1994) em que, não houve efeitos positivos do diálogo durante a leitura compartilhada, porém a análise das perguntas feitas possibilitou ver que a maior parte delas não tinha relação com aspectos temáticos relevantes para a compreensão da história (por exemplo, pedir para a criança inferir o que os personagens haviam comido no café-da manhã a partir de uma ilustração, quando essa informação era irrelevante para a compreensão da história).

Para aumentar a probabilidade de que as intervenções pudessem de fato evocar verbalizações sob controle temático da narrativa, e não sob controle de aspectos irrelevantes (por exemplo, aspectos formais, como a sequência exata de palavras ou detalhes periféricos do enredo), uma análise do texto em termos de suas funções narrativas foi apresentada à mediadora para estudo e treino antes de cada sessão. A análise do texto em funções narrativas (Flores et al., 2014) também possibilitou avaliar aspectos do comportamento verbal relacionados ao texto usado ao invés de fazê-lo por meio de escores em testes padronizados que não têm relação com os textos lidos na intervenção, como a maior parte dos estudos sobre LD (e.g. Lever \& Sénéchal, 2011).

A identificação de funções feita no presente trabalho é uma forma de definir unidades tematicamente relevantes da narrativa (Barthes, 1966/2009), sob a qual um leitor fica sob controle quando se diz que compreendeu uma história. Nesse contexto, elas podem se constituir de vários fragmentos do texto, que não possuem entre si uma relação de encadeamento linear, e sim de relações temáticas mais ou menos complexas. Os presentes resultados sugerem que basear a estimulação suplementar e o reforçamento diferencial nessas dimensões temáticas da narrativa pode ser importante para se obter ganhos na compreensão leitora. Nesse contexto, importa lembrar que, para a compreensão de uma história, não é necessário memorizar todos os eventos, nem esta é condição suficiente para a compreensão. A maioria das pessoas não é capaz de recitar todos os aconte- 
cimentos de um romance e, ainda assim, é possível dizer que elas compreenderam a história, desde que mostrem domínio em relação aos seus pontos-chave (que não se limitam aos eventos, podendo incluir relações de eventos entre si e com eventos anteriores ou posteriores à cronologia da história, motivos e disposições dos personagens etc.).

O presente estudo dá sustentação aos achados de outros estudos que apontam para a importância de que aquele que interage com a criança durante a leitura fique sensível ao seu comportamento momento a momento (e.g. Neuman \& Gallagher, 1994; Van de Pol et al. 2010) de modo a proporcionar a estimulação suplementar e o reforçamento diferencial de acordo com a necessidade. Nesse sentido, nem todo diálogo é igualmente positivo para desenvolver a compreensão da narrativa. Não faltou diálogo nas condições de leitura dialógica em Rogoski et al. (2013), mas estes não foram eficazes em aumentar a compreensão narrativa das crianças. Isso corrobora a análise crítica feita no estudo de Yaden (2003) da afirmação de que toda leitura interativa de histórias infantis seria uma oportunidade de scaffolding. Pelo contrário, observações naturalistas evidenciam que, muitas vezes, as conversas ao redor do livro são repletas de interrupções, falas sem relação com a atividade, perguntas não respondidas e temas não retomados. Por exemplo, é comum os pais fazerem perguntas, mas não proporcionarem estimulação suplementar quando a resposta não é dada, oferecendo imediatamente um modelo de resposta, sem pedir que a criança a reproduza ou passando para outra pergunta (Yaden, 2003). Em outras palavras, não basta planejar perguntas, é necessário planejar contingências.

A importância da assistência crescente e da estimulação suplementar têm sido pouco enfatizada nos treinamentos em LD. Os vídeos e as atividades de role-playing usados para ensinar a leitura dialógica. (e.g. Arnold et al., 1994; Zevenbergen \& Whitehurst, 2003) tendem a se centrar nos tipos de perguntas a serem feitas (e.g., o acrônimo CROWD, proposto para ensinar cinco tipos diferentes de perguntas, e.g., Pillinger \& Wood, 2013). A consequenciação é descrita de forma ampla, recomendando-se o elogio e a ampliação das falas dos ouvintes (e.g., Zevenbergen \& Whitehurst, 2003). O presente estudo aponta para a importância de treinar formas de interagir mais específicas para obter ganhos na compreensão narrativa.
Pesquisas futuras deverão (a) replicar o presente estudo com mais participantes, usando um delineamento de linha-de-base múltipla por participante, com uma linha de base de leitura não dialógica e textos independentes e (b) investigar a aplicabilidade dos princípios sugeridos pelos presentes resultados no treinamento de pais para a aplicação da LD nos lares.

\section{Referências}

Arnold, D. H., Lonigan, C. J., Whitehurst, G. J., \& Epstein, J. N. (1994). Accelerating language development through picture book reading: Replication and extension to a videotape training format. Journal of Educational Psychology, 86(2), 235- 43.

Barthes, R. (2009). Introdução à análise estrutural da narrativa. In R. Barthes, A. J. Greimas, C. Bremond, U. Eco, V. Morin, J. Gritti, C. Metz, T. Todorov, \& G. Genette. Análise Estrutural da Narrativa (6. ed.) (pp.19-62) (M. B. Z. Pinto, Trad.). São Paulo: Vozes [Originalmente publicado em 1966].

Camelo, M. L., \& Souza, C. B. A. (2009). Leitura dialógica, consciência fonológica e o desenvolvimento de repertórios verbais. In R. C. Wielenska (Ed.). Sobre Comportamento e Cognição (Vol. 24, pp. 159-168). Santo André: ESETec.

Dickinson, D.K., \& Smith, M.W. (1994). Long-term effects of preschool teachers' book readings on low-income children's vocabulary and story comprehension. Reading Research Quarterly, 29, 104-122.

Flores, E. P., Pires, L., \& Souza, C. B. A. (2014). Dialogic reading of a novel for children: Effects on text comprehension. Paidéia, 24(58), 243251.

Flynn, K. S. (2011). Developing children's oral language skills through dialogic reading: Guidelines for implementation. Teaching Exceptional Children, 44(2), 8-16.

Gettinger, M., \& Stoiber, K. C. (2014). Increasing opportunities to respond to print during storybook reading: Effects of evocative print-referencing techniques. Early Childhood Research Quarterly, 29(3), 283-297.

Lever, R., \& Sénéchal, M. (2011). Discussing stories: How a dialogic reading intervention im- 
proves kindergartners' oral narrative construction. Journal of Experimental Child Psychology, 108(1), 1-24.

Marques Neto, J.C., Venegas, S., \& Octobre, S. (2013). Leitor de hoje, mediador de amanhã. In D. Prade \& P. P. Leite (Eds.). Crianças e jovens no século XXI - leitores e leituras (pp. 150-159). São Paulo: Livros da Matriz.

Mol, S. E., Bus, A. G., de Jong, M. T., \& Smeets, D. J. (2008). Added value of dialogic parentchild book readings: A meta-analysis. Early Education and Development, 19(1), 7-26.

Neuman, S.B., \& Gallagher, P. (1994). Joining together in literacy learning: Teenage mothers and children. Reading Research Quarterly, 29, 382-401.

OECD (2013). Pisa 2012 Results in Focus. What 15-year-olds know and what they can do with what they know. Disponível em http://www. oecd.org/pisa/keyfindings/pisa-2012-results-overview.pdf

Pillinger, C., \& Wood, C. (2013). A small-scale comparison of the relative impact of dialogic and shared book reading with an adult male on boys' literacy skills. Journal of Early Childhood Literacy, 13(4), 555-572.

Reyes, Y. (2012). Ler e brincar, tecer e cantar: Literatura, escrita e educação [Rodrigo Petronio, Trad.]. São Paulo: Pulo do Gato.

Rogoski, B. N., Flores, E. P., Araújo, B. S., Conceição, J. A., Barros, L. M., Coelho, R. F., \& Souza, C. B. A. (2013, julho). Leitura Dialógica com crianças alfabetizadas: Efeitos sobre a nomeação, a caracterização e a identificação de sentimentos dos personagens durante a recontação. Trabalho apresentado no XXXIV Congresso Interamericano de Psicologia, Brasília, DF, Brasil. Resumo recuperado de http://www. sip2013.org/pdf/AnaisCIP-VrsFinal04.pdf.

Skinner, B. F. (1957). Verbal Behavior. New York: Apple-Century-Crofts.

Swanson, E. A., Wanzek, J., Petscher, Y., Vaughn, S., Heckert, J., Cavanaugh, C., Kraft, G., \& Tackett, K. (2011). A synthesis of read-aloud interventions on early reading outcomes among preschool through third graders at risk for reading difficulties. Journal of Learning Disabilities, 44(3), 258-27

Van de Pol, J., Volman, M., \& Beishuizen, J. (2010). Scaffolding in teacher-student interaction: A decade of research. Educational Psychology Review, 22, 271-296.

Vigotsky, L. S. (1998). A Formação social da mente (M. Cole, V. John-Steiner, S. Scribner, \& E. Souberman E.) (J.C. Neto, L.S. Barreto, S.C. Afeche, Trads.). São Paulo, SP: Martins Fontes (Originalmente publicado em 1978).

Wasik, B. A., \& Hindman, A. H. (2014). Understanding the active ingredients in an effective preschool vocabulary intervention: An exploratory study of teacher and child talk during book reading. Early Education and Development, 25(7), 1035-1056.

Whitehurst, G. J., Falco, F. L., Lonigan, C. J., Fischel, J. E., DeBaryshe, B. D., Valdez-Menchaca, M.C., \& Caulfieild, M. (1988). Accelerating language development through picture book reading. Developmental Pyschology, 24(4), 552-559.

Whitehurst, G. J., \& Lonigan, C. J. (1998). Child development and emergent literacy. Child Development, 69(3), 848-872.

Whitehurst, G. J., Zevenbergen, A. A., Crone, D. A., Schultz, M. D., Velting, O. N., \& Fischel, J. E. (1999). Outcomes of an emergent literacy intervention from Head Start through second grade. Journal of Educational Psychology, 91, 261-272. Yaden, D.B., Jr. (2013). Parent-child storybook reading as a complex adaptive system: Or "an igloo is a house for bears". In A. van Kleeck, S. A. Stahl, \& E. B. Bauer (Eds.). On Reading Books to Children: Parents and Teachers (pp. 336-362). New York: Routledge.

Zevenbergen, A.A., Whitehurst, G.J., \& Zevenbergen, J.A. (2003). Effects of shared-reading intervention on the inclusion of evaluative devices in narratives of children from low-income families. Journal of Applied Developmental Psychology, 24, 1-15.

\section{Informações do Artigo}

\section{Histórico do artigo:}

Submetido em: 18/05/2015

Primeira decisão editorial: 05/09/2015

Aceito em: 07/10/2015

Editor associado: Candido V. B. B. Pessôa 